Jorun Nyléhn har doktorgrad i biologi fra Universitet i Oslo. Deretter arbeidet hun som forsker ved Institutt for lærerutdanning og skoleutvikling ved UiO, med komparativ utdanningsforskning og naturfagdidaktikk tilknyttet Trends in International Mathematics and Science Study (TIMSS). Hun arbeider nå som førsteamanuensis og underviser primært i biologi og naturfagdidaktikk i grunnskolelærerutdanningen for 5.-10. trinn.

\title{
JORUN NYLÉHN
}

Førsteamanuensis ved Institutt for matematikk og naturfag, Fakultet for humaniora, idrett og utdanningsvitenskap,

\section{To broer mellom biologi og læring}

\begin{abstract}
Human biology, in terms of organization of our brains and our evolutionary past, constrains and enables learning. Two examples where neurobiology and evolution influences learning are given and discussed in relation to education: mirror neurons and adaptive memory. Mirror neurons serves imitation and understanding of other peoples intentions. Adaptive memory implies that our memory is an adaptation influenced by our evolutionary past, enabling us to solve problems in the present and in the future. Additionally, the aim is to contribute to bridges between natural and social sciences in an attempt to achieve an improved understanding of learning. The relevance of perspectives on learning founded in biology are discussed, and the article argues for including biological perspectives in discussions of education and learning processes.
\end{abstract}

\section{INTRODUKSJON}

Biologiske forutsetninger for læring og undervisning er et omdiskutert tema (Tardif, Doudin \& Meylan, 2015). Mens flere forfattere ønsker å bygge en bro fra biologi til utdanningsforskning (Coch \& Ansari, 2009; Tardif et al., 2015), ønsker andre å holde disse feltene atskilt (Bruer, 1997). Denne artikkelen søker å bygge broer mellom biologi og læring gjennom søk og sammenstilling av litteratur.

Naturvitenskap og samfunnsvitenskap sees iblant på som svært forskjellige (Snow, 1960). Å bygge broer fra biologi til utdanningsforskning kan dermed være et relativt langt steg. Likevel ønsker mange å gjøre dette, siden de anser hjernens biologi som tett sammenknyttet med læring (Edelenbosch, Kupper, Krabbendam \& Broerse, 2015). Edelenbosch et al. (2015) poengterer at faggrenser er sosialt konstruerte. Edward O. Wilson (1999) har skrevet en bok om å forene naturvitenskap og humaniora, Consilience, der han argumenterer for å kombinere kunnskap fra ulike fagfelt for å oppnå en dypere forståelse av fenomener. Consilience betyr å sette sammen, å lenke sammen kunnskap og teori på tvers av disipliner for å skape en felles plattform. Å krysse faggrenser kan gi nye muligheter for kunnskapsvekst (Wilson, 1999, s. 9).

Evolusjonsbiologi regnes som et samlende teoretisk rammeverk for samtlige emner i biologi, og står i en særegen posisjon til å binde sammen fagtradisjoner (Mesoudi, Whiten \& Laland, 2006). Gjennom 
evolusjonsteorien kan de ulike feltene innen biologi sees i sammenheng, slik at disiplinene kan inspirere og bidra til utviklingen i andre felt. Mesoudi et al. (2006) har postulert at evolusjonsbiologi også kan være et sammenbindende og overordnet rammeverk for deler av samfunnsvitenskapene, slik at de i større grad kan bidra til å utvikle hverandre.

Mange ulike retninger finnes som tar for seg forskjellige aspekter ved læring (Alexander, Schallert \& Reynolds, 2009). Alexander et al. (2009) framholder at motsetninger mellom ulike syn på læring ikke skyldes at de er inkompatible, men at de enkelte tradisjonene forholder seg til ulike aspekter ved læringsprosesser. Geary (2009) er enig med Alexander et al. (2009), og foreslår å bruke evolusjonsteori som møtepunkt mellom de ulike læringssynene.

$\AA$ A hente kunnskap og inspirasjon fra biologi i utarbeidelsen av læringsteori er ikke nytt. Sentrale læringsteoretikere som Jean Piaget og Lev S. Vygotsky benyttet idéer fra evolusjonsbiologi i arbeidene sine (Wozniak, 2009). Begge var blant annet inspirert av den amerikanske psykologen James Mark Baldwin. Baldwin publiserte artikler om kognitiv læringsteori og betydningen av sosialt miljø, som Piaget og Vygotsky senere videreutviklet (Piaget, 1969; Vygotskij, 2004). Baldwin var på sin side inspirert av Charles Darwin, og evolusjonsteori var et viktig grunnlag for idéene hans (Wozniak, 2009). Vygotsky ønsket helhetlige forklaringer på læring som inkluderte mekanismer i hjernen, evolusjonshistorie, individuell utvikling, og beskrivelse av miljøet (Cole \& Scribner, 1978, s. 6).

I et evolusjonært perspektiv er det tydelig at kognitive og sosiale aspekter både kan og bør sees i sammenheng (Sperber \& Hirschfeld, 2004). Nettopp sosiale interaksjoner har trolig vært essensielt for utviklingen av hjernene våre (Dunbar, 2003). Vi er laget for å ta del i et samfunn, lære av og dele kunnskap med andre, omstrukturere kunnskapen til eget bruk, og bruke kreative evner på tillært kunnskap og videreutvikle den (Geary, 2008a). Å overlevere kunnskap fra en generasjon til den neste har vært essensielt for menneskets utvikling av kultur. Læring og overføring av kunnskap er fundamentale aspekter ved mennesket som art, en forutsetning for vår kultur og eksistens (Nettle, 2009).

Det er et langt steg fra biologiske forklaringer til praktisk undervisning. Denne artikkelen har fokus på potensialet for brobygging mellom biologi, spesielt nevrobiologi og evolusjonsbiologi, og forståelsen av læring. For å avgrense det enorme feltet som åpner seg i det man beveger seg inn på nevrobiologi, evolusjon og læringsteori, har jeg valgt to fokusområder: Speilnevroner og adaptiv hukommelse. Fokusområdene er valgt fordi de representerer nyere forskning som er relatert til både biologi og læring. Videre finnes det empiriske studier på begge områder. Strukturerte søk i litteraturen er foretatt for å undersøke kunnskapsgrunnlaget for broer mellom biologi og forståelse av læring på disse to områdene. Formålet er å bidra til å finne felles grunn mellom biologi og læring, å søke sammenheng i kunnskapen, det Edward O. Wilson (1999) kalte consilience.

Men et spørsmål er hva slags broer vi har kunnskap til å bygge, et annet spørsmål er om dette er verdifull kunnskap for lærere. Nytten av å se læring i sammenheng med biologi blir derfor diskutert i siste del av artikkelen: Trenger vi kunnskap om nevrobiologi og evolusjon for å forstå læring?

\section{FRAMGANGSMÅTE}

Artikkelen er basert på et strukturert litteratursøk i internasjonale anerkjente tidsskrifter, basert på retningslinjene PRISMA (Preferred Reporting Items for Systematic reviews and Meta-Analyses), se Moher, Liberati, Tetzlaff og Altman (2009). Søkemotorene Oria og Google scholar er benyttet. Oria er en søkemotor som gir tilgang til bibliotekets samlede ressurser, blant annet databasene EBSCO, ProQuest og SAGE. For speilnevroner ble en rekke søk foretatt med kombinasjoner av søkeordene «mirror neurons», «education», «learning», «school», «imitation» og «intentions». For adaptiv hukommelse ble en rekke søk foretatt med kombinasjoner av søkeordene «adaptive memory», «hy- 
pothesis», «learning», «education», «school», «evolution», «survival value» og "survival processing». Søkene på speilnevroner ga totalt 2849 treff i Oria og 280900 treff i Google scholar, mens søkene på adaptiv hukommelse ga 13365 treff i Oria og 26421 i Google scholar. Siste litteratursøk ble foretatt 6 . august 2015 .

De 10 første treffene fra hver kombinasjon av søkeord ble tatt med fra søkene i Google scholar. For søkene med mer enn 100 treff i Oria, ble det foretatt nye søk begrenset til årene 2014 og 2015. For speilnevroner ble til sammen 460 artikler fra søk i Oria og 90 treff fra Google scholar innledende vurdert, for adaptiv hukommelse gjaldt dette 619 artikler fra søk i Oria og 150 treff fra Google scholar. Duplikater ble tatt bort. Titler og sammendrag ble vurdert mot en rekke eksklusjonskriterier. Artikler ble ekskludert dersom de primært omhandlet lærevansker, ulike diagnoser, motorisk læring, læring av musikk, evolusjon av språk, lek hos små barn, individuelle forskjeller, kulturforskjeller, andre arter enn mennesket, fysisk sykdom, effekter av aldring, ikke var fagfellevurdert eller ikke forelå på engelsk eller et nordisk språk.

Deretter ble gjenværende artikler gjennomgått og vurdert. Noen få artikler fra referanselistene ble inkludert. Totalt 48 artikler om speilnevroner og 59 artikler om adaptiv hukommelse ble gjennomgått. Artiklene ble først nøye lest, deretter ble argumenter og empiriske funn av betydning for artikkelens problemstilling samlet i en tekstfil. Å søke etter eventuelle motstridende resultater ble vektlagt. Studiene ble sammenfattet innenfor rammene av problemstillingen. Av plasshensyn har referanser med tilsvarende resultater blitt utelatt. En komplett liste over artiklene kan fås fra forfatteren på forespørsel.

\section{SPEILNEVRONER OG SOSIAL LAERING}

Speilnevroner er et sentralt og innflytelsesrikt funn i nevrobiologi fra de siste tiårene (Casile, 2013). Dette ble oppdaget hos aper (makaker) tidlig på 1990-tallet (di Pellegrino, Fadiga, Fogassi, Gallese \& Rizzolatti, 1992). Forskere så at et område i hjernen, som regel et enkelt nevron, ble aktivert hos en ape da den tok et objekt ut av en boks. Akkurat samme område ble aktivert når apen så at en annen tok et tilsvarende objekt. Funnet av speilnevroner har igangsatt mye forskning og diskusjon innen nevrobiologi også hos mennesker (Heyes, 2010; Hickok, 2013).

Et tilsvarende system gjelder trolig også for oss (Casile, 2013). Til forskjell fra makaker har mennesker sannsynligvis et mer avansert system, der speilnevroner virker sammen med andre nevroner for å kunne ivareta flere funksjoner (Iacoboni, 2005; Oztop, Kawato \& Arbib, 2013). Hos mennesker tyder forskningsresultatene på at speilnevronene også er ansvarlig for evnen til å imitere. Aper kan trolig forstå et enkelt mål og forsøke å kopiere det, mens mennesker kan forstå hvordan et mål er oppnådd, og splitte en handling opp i ulike komponenter (Gog, Paas, Marcus, Ayres \& Sweller, 2009).

Flere forskere har satt undervisning og læring i relasjon til speilnevroner (Ayres, Marcus, Chan \& Qian, 2009; Brucker, Ehlis, Häußinger, Fallgatter \& Gerjets, 2015). Speilnevronene kan endre seg hos voksne mennesker, og utvikler seg med sosial interaksjon (Heyes, 2010). Læring ved observasjon er en av de mest grunnleggende metodene for læring (Bandura, 1986, s. 47), og speilnevroner kan tenkes å bidra til å forklare dette (Gog et al., 2009). Å lære av andre mennesker ved å observere og imitere har trolig vært en svært viktig faktor i evolusjon av hjernene våre (Sweller \& Sweller, 2006). Før skriftspråket kom lærte vi enten av andre mennesker eller ved selv å prøve og feile, og sosial læring og kumulativ kultur innebærer at informasjon overføres mellom mennesker (Nettle, 2009).

Speilnevroner rolle i å forstå handlinger og intensjoner (Gog et al., 2009) er også interessant. Selv små barn synes å forstå intensjoner. Babyer imiterer ikke nødvendigvis direkte, men tolker handlinger ut fra mål og kontekst, og kan velge en annen måte for å oppnå samme mål (Gog et al., 2009). Målet for en handling synes å være det viktige for å aktivisere speilnevronene, ikke det å observere at 
et menneske faktisk gjør noe (Sinigaglia, 2013). Å se en robotarm gjøre det samme har liknende effekt (Stanley, Gowen \& Miall, 2010). Å høre beskrivelser av hva andre mennesker gjør, og å forestille seg en handling, kan også aktivere speilnevroner (Ocampo \& Kritikos, 2011).

Mennesker kopierer ikke andre direkte. Hvordan vi tolker en handling og hva vi velger å legge vekt på er et resultat av både nevrobiologiske begrensninger og erfaringer (Immordino-Yang, 2008). Speilnevronene aktiveres sterkere når handlingene vi observerer er utført i en meningsfylt kontekst der intensjonen ved handlingen kommer fram (Iacoboni, 2005). Forkunnskaper er også vist å ha betydning for aktiveringen av speilnevroner (Stanley et al., 2010).

Kvinner har flere (Yawei et al., 2008) og mer aktive (Stanyon \& Bigoni, 2014) speilnevroner enn menn. Speilnevroner er trolig viktige for empati med andre mennesker, gjennom å binde individer sammen som en gruppe, og skape en felles forståelse av aktiviteter og intensjoner (Stanyon \& Bigoni, 2014). At kvinner har flere og mer aktive speilnevroner enn menn kan tenkes å ha betydning for skolen. A skille biologiske fra erfaringsbetingede effekter av kjønn på skoleprestasjoner er vanskelig (Ball, Balthazart \& McCarthy, 2014). Ball et al. (2014) har forsøkt å skille effekter av biologisk kjønn og miljøpåvirkning, og fant at fortrinnet gutter hadde i matematikk i en del land trolig var miljøbetinget, mens jentenes fortrinn på andre områder som lesing trolig hadde en basis i biologiske forskjeller. Her er det selvsagt mye mer enn speilnevroner som kan spille inn.

At speilnevronene aktiveres sterkere når en handling utføres i en meningsfylt kontekst der formålet kommer klart fram (Iacoboni, 2005) viser en tydelig sammenheng med pedagogiske anbefalinger. At kvinners speilnevroner aktiveres lettere enn menns kan bety at de har lettere for å tolke formål (Immordino-Yang, 2008), og kanskje kan jenter dermed dra nytte av undervisning som er mindre eksplisitt enn det gutter har behov for. Gog et al. (2009) diskuterer speilnevronenes betydning for undervisning, og konkluderer med at selv om mer forskning er nødvendig, gir det et interessant bidrag til forståelsen av læring.

\section{HUKOMMELSE ER EN EVOLUSJONAR TILPASNING}

At hukommelsen vår er en evolusjonær tilpasning er en annen biologisk begrunnet hypotese om læring som har fått mye oppmerksomhet, forskning og diskusjon knyttet til seg, se for eksempel Howe og Otgaar (2013). Å huske hendelser sees som et resultat av evolusjonær tilpasning, vi husker fortida fordi det er en hjelp til å overleve i nåtida og planlegge framtida (Shohamy \& Adcock, 2010).

Hukommelse er postulert å ha røtter tilbake til perioden da dyreriket oppsto og raskt ble svært mangfoldig, i Kambrium (Ginsburg \& Jablonka, 2010). Men det er ikke bare at vi husker som kan tenkes å ha et evolusjonært bakteppe. Også hva vi husker er trolig influert av tidligere tiders seleksjonspress. Nairne og Pandeirada (2010) har gjennom flere eksperimenter vist at informasjon lettere blir husket dersom den er relatert til overlevelse i et fortidsmiljø. Både direkte informasjon om overlevelse og nøytrale momenter som en person har tenkt igjennom i forhold til overlevelse er vist å bli husket bedre (Howe \& Otgaar, 2013). Dette gjelder både for barn og voksne (Aslan \& Bäuml, 2012).

At hukommelse er en tilpasning og at vi har lettere for å huske nyttig informasjon synes av mange forfattere opplagt (Howe \& Otgaar, 2013; Nairne \& Pandeirada, 2010; Otgaar, Howe, Smeets \& Garner, 2014). Vi har ofte gode følelser og høy motivasjon for det som er til nytte for oss og våre nærmeste (Sperber \& Hirschfeld, 2004). Mekanismen bak er derimot omdiskutert (Howe \& Otgaar, 2013). Mens for eksempel Nairne og Pandeirada (2010) framholder at vi trolig har en modul eller flere for overlevelsesrelatert kunnskap, har blant annet Howe og Otgaar (2013) postulert at det er generelle mekanismer, for eksempel sterkere følelser knyttet til informasjon som oppleves som viktig, som har betydning for at vi husker enkelte ting bedre. 
Selv om mekanismen bak ikke er avklart, finnes det mye empiri for at informasjon som er eller kan knyttes til overlevelse huskes bedre (Nairne \& Pandeirada, 2010; Otgaar et al., 2014). Dette gjelder ikke bare gjenfortelling av fakta, men det synes også å være økt potensiale for senere anvendelse av kunnskapen. Howe og Derbish (2010) postulerer at informasjonen trolig knyttes opp til større kognitive nettverk. Flere eksperimenter tyder på at informasjonen ikke bare huskes, men også bidrar til bedre problemløsning senere, og forfatterne argumenterer for at dette skyldes måten den overlevelsesrelaterte kunnskapen lagres i hjernen.

Hypotesen om adaptiv hukommelse er også testet i tilknytning til undervisning. Prokop og Fancovicova (2014) fant at elever lettere husket arter som kunne spises eller var giftige. Elevene hadde også lettere for å huske bær som viste tegn på å være spiselige eller giftige, sammenliknet med umodne, selv om de ikke visste om dette var tilfelle. Røde bær er ofte spiselige, svarte ofte giftige, og grønne er oftest umodne. Elevene husket bedre røde og svarte enn grønne bær, noe som kan begrunnes evolusjonært (Prokop \& Fancovicova, 2014). VanArsdall, Nairne, Pandeirada og Blunt (2013) fant at levende organismer ble lettere husket enn ting. Dette gjaldt også informasjon som ble relatert til levende organismer. Wilson, Darling og Sykes (2011) fant at spillere av memory hadde lettere for å huske plasseringen av bilder som har hatt overlevelsesverdi knyttet til seg evolusjonært sett, som rovdyr. Hukommelsen var bedre for rovdyr enn våpen, og forfatterne postulerer at dette er evolusjonært betinget. Forfatterne refererer videre til flere studier som har vist økt oppmerksomhet overfor slanger, spesielt slanger i bevegelse, edderkopper, og sinte ansikter (Wilson et al., 2011).

Dopamin er den viktigste nevrotransmitteren i hjernen (Hong, 2013). Denne nevrotransmitteren er en del av hjernens belønningssystem, og bidrar trolig til økt hukommelse for det som er viktig for oss (Shohamy \& Adcock, 2010). Dopaminets virkning er derfor postulert å være avgjørende for adaptiv hukommelse. Utvelgelsen av informasjon skjer ubevisst, og sannsynligvis har både erfaring og evolusjonshistorie betydning for hva vårt ubevisste legger vekt på (Shohamy \& Adcock, 2010). At nettopp dopamin, som er en del av hjernens belønningssystem også er nært knyttet til hukommelse, viser hvordan læring og affektive faktorer er nært knyttet sammen (Shohamy \& Adcock, 2010). Teorien og eksperimentene rundt adaptiv hukommelse viser at det ikke er tilfeldig hva vi husker, men betinget av hvem vi er og hva som er viktig for oss (Alexander et al., 2009).

En mulighet som springer fram av dette er å benytte overlevelsesrelaterte aspekter av biologi for å lette innlæringen av andre fag. Vi kan bruke det vi har hatt nytte av i evolusjonær tid som en inngang til mer abstrakte emner. Dette er foreslått i mer vid forstand av David Geary (2009) som deler kunnskap i to hovedkategorier: primær og sekundær. Med primærkunnskap menes informasjon som vi har hatt nytte av i evolusjonær tid, og som hjernen har hatt mulighet til å evolvere innstillinger for å lære raskt (artskunnskap, språk, sosiale interaksjoner, bruk av verktøy). Med sekundærkunnskap menes nyere kunnskapsområder (lesing, skriving, avansert matematikk) som ikke eksisterte i evolusjonær tid, men som vi må bruke den generelle læringskapasiteten vår for å lære og forstå. Geary (2009) postulerer at primærkunnskap kan brukes til å lettere lære sekundærkunnskap. Dette er også interessant i forhold til grunnleggende ferdigheter, som blant annet innebærer at lesing, skriving og regning legges inn i alle fag. Dette er nettopp hva Geary (2009) kaller sekundærkunnskap, og i blant annet naturfag finnes det mange gode muligheter for å koble grunnleggende ferdigheter opp mot primærkunnskap.

De fleste av artiklene er basert på empiriske data, mens noen dreier seg om teoretiske perspektiver (Alexander et al., 2009; Geary, 2009). Forskningsfeltene er relativt nye, og få miljøer er engasjert i å forske på dette relatert til læring. Lite er gjort i reelle undervisningssituasjoner, et unntak er Prokop og Fancovicova (2014). Noen har foretatt eksperimenter på elever (Ayres et al., 2009) eller yngre studenter (Brucker et al., 2015) for å belyse læreprosesser. Andre, som Gog et al. (2009), diskuterer funnene i forhold til undervisning, men har ikke testet de postulerte implikasjonene. Mye forskning gjenstår selvsagt på disse områdene. 


\section{TRENGER VI BIOLOGI FOR Å FORSTÅ LAERING?}

Sousa (2010) poengterer at gode lærere og pedagoger lenge har funnet måter å undervise på som har vist seg effektive og fungerer i deres klasserom. Dette har de funnet ved erfaring, uten kjennskap til nevrobiologi eller evolusjonsteori. Evolusjon er også et emne som skaper kontroverser, blant annet ut fra ulike religiøse overbevisninger (Halpern, 2008). Andre har hevdet at avstanden er for stor mellom biologi og utdanningsvitenskap til at nevrobiologi kan være relevant for utdanning (Bruer, 1997). Flere myter om hva hjerneforskning betyr for utdanning har blitt spredt, egnet til å skape misforståelser, overdreven tro på nevrobiologi, eller til å forkaste den (Sousa, 2010; Tardif et al., 2015). Trenger vi å inkludere biologiske forklaringer på læring? I det følgende vil jeg diskutere ulike sider ved å integrere biologiske årsaksforklaringer i synet på læring.

Er det tilstrekkelig å basere undervisning på erfaring og annen teori enn biologi? Et grunnleggende svar på dette er at å vite hvorfor noe fungerer er mer enn å ha erfart at det virker (Sousa, 2010). Strategiene vil heller ikke alltid virke som ønsket i ulike sammenhenger. Å vite mer om hvordan hjernen prosesserer kunnskap og ferdigheter kan bidra til økt forståelse for hvorfor ulike strategier virker eller ikke i forskjellige kontekster (Sousa, 2010). Mesoudi et al. (2006) og Smith (2007) ønsker en syntese av naturvitenskap og sosiale vitenskaper for å forstå læring i dybden, og se hjernen og kroppen som et komplekst system i interaksjon med både sosialt og naturlig miljø. Kanskje er dette spesielt nyttig for biologer, som dermed kan oppleve at kunnskap om læring veves tettere sammen med deres øvrige faglige bakgrunn. For andre kan derimot biologiske emner skape kontroverser eller avstand (Halpern, 2008). Evolusjonsteori er kontroversielt i en del religiøse grupper, og genetikk tolket som genetisk determinisme oppfattes av flere som en motsetning til sosiale vitenskaper (Halpern, 2008). Dette gir to problemer: biologien kan bli møtt av negative følelser og uvilje (Sinatra, Doutherland, McConaughy \& Demastes, 2003), og et feilaktig bilde av biologien kan presenteres gjennom stråmannsargumentasjon (Sousa, 2010).

En nyansert presentasjon av biologi er viktig av flere grunner. Trening av hjernen selges allerede kommersielt, mer eller mindre basert på reelle vitenskapelige funn (Melby-Lervåg \& Hulme, 2013). Medikamenter for hukommelse og arbeidsminne er under utvikling og til dels en realitet (Farah et al., 2004). Mange eksempler på myter om biologi og nevrobiologiens betydning for læring kan finnes hos Tardif et al. (2015). Et nyansert bilde er også egnet til å imøtegå svart-hvite tolkninger der biologi, gener og arv sees som en motsetning til miljø og sosiale faktorer (Fischer \& Heikkinen, 2010).

Biologi kan også bidra til gode følelser. Evolusjon kan brukes til å skape undring, for eksempel gjennom å inkludere et langt tidsperspektiv (Delgado, 2014). En hypotese er at hukommelse oppsto for over 500 millioner år siden (Ginsburg \& Jablonka, 2010), og bidro til at dyreriket raskt ble så stort og mangfoldig i Kambrium (Shu, 2008). Evolusjon kan vise hvordan vi er i slekt med resten av den levende naturen, og bidra til dyp respekt og undring (Delgado, 2014). Kontroverser rundt ulike syn på evolusjon kan også være utgangspunkt for gode diskusjoner i klasserommet (Basel, Harms, Prechtl, Weiz \& Rothgangel, 2014).

Som nevnt i innledningen argumenterer Mesoudi et al. (2006) for å bruke evolusjonsteorien som et integrerende, overgripende rammeverk i sosiale vitenskaper. Å bruke evolusjon som rammeverk kan vise at ulike fagdisipliner ser på komplementære, og ikke motstridende, aspekter ved den samme virkeligheten (Mesoudi et al., 2006). I et metaperspektiv gjelder dette også biologi og religion, og å møte motstridende synspunkter kan være en kilde til personlig vekst. Dette er vanskelig der det er sterk følelsesmessig tilknytning. Geary (2008b) poengterer at selv om evolusjon er kontroversielt hos enkelte grupper er det ikke tilstrekkelig grunn til å ekskludere temaet.

Bruer (1997) argumenterer for at nevrobiologi bør holdes atskilt fra utdanningsforskning, men svært mye har skjedd siden denne kritikken kom (Sousa, 2010). Coch og Ansari (2009) ønsker aktive forskerfellesskap der både nevrobiologer og utdanningsforskere deltar. Forfatterne argumenterer for at nevrobiologiske funn ikke kan gi direktiver for undervisning alene, men kan danne utgangspunkt 
for hypoteser som deretter bør testes empirisk i klasserommet. Nairne og Pandeirada (2010) har på tilsvarende vis testet hypoteser om læring med utspring i evolusjon. Edelenbosch et al. (2015) ønsker flere personer som befinner seg i grenselandet mellom biologi og utdanning, og som kan bidra til å lage broer mellom feltene. Her er god informasjonsflyt essensielt. Gardner (2009) poengterer at å knytte sammen biologi og utdanning gir muligheter for bedre forståelse for læring enn å holde fagfeltene atskilt, men det er viktig at prosessen baseres på respekt og refleksjon.

Speilnevronenes funksjon kan også brukes til å illustrere en intensjon bak denne artikkelen: De bidrar til at vi forstår årsakene bak en handling bedre (Ocampo \& Kritikos, 2011). Både nevrobiologi og evolusjon kan bidra med svar (Geary, 2009; Sousa, 2010). A forstå hvorfor er en vanlig drivkraft hos mange mennesker (DeYoung et al., 2011), noe som bidrar til mening (Wilson, 1999, s. 9). Slik kan også biologi inngå sammen med andre fagfelt for en dypere og mer helhetlig forståelse av læring.

\section{LITTERATURLISTE}

Alexander, P. A., Schallert, D. L., \& Reynolds, R. E. (2009). What Is Learning Anyway? A Topographical Perspective Considered. Educational Psychologist, 44(3), 176-192.

Aslan, A., \& Bäuml, K.-H. T. (2012). Adaptive memory: Young children show enhanced retention of fitness-related information. Cognition, 122(1), 118-122.

Ayres, P., Marcus, N., Chan, C., \& Qian, N. (2009). Learning hand manipulative tasks: When instructional animations are superior to equivalent static representations. Computers in Human Behavior, 25(2), 348-353. http://www.sciencedirect.com/science/article/pii/So747563208002240

Ball, G. F., Balthazart, J., \& McCarthy, M. M. (2014). Is it useful to view the brain as a secondary sexual characteristic? Neuroscience \& Biobehavioral Reviews, 46, 628-638. http://www.sciencedirect.com/science/article/pii/So149763414002073

Bandura, A. (1986). Social foundations of thought and action: A social cognitive theory. Engelwood Cliffs, NJ: Prentice Hall.

Basel, N., Harms, U., Prechtl, H., Weiz, T., \& Rothgangel, M. (2014). Students' arguments on the science and religion issue: the example of evolutionary theory and Genesis. Journal of Biological Education, 48(4), 179-187.

Brucker, B., Ehlis, A.-C., Häußinger, F. B., Fallgatter, A. J., \& Gerjets, P. (2015). Watching corresponding gestures facilitates learning with animations by activating human mirror-neurons: An fNIRS study. Learning and Instruction, 36(0), 27-37. http://www.sciencedirect.com/science/article/ pii/So959475214001066

Bruer, J. T. (1997). Education and the Brain: A Bridge Too Far. Educational Researcher, 26(8), 4-16. http://www.jstor.org/stable/1176301

Casile, A. (2013). Mirror neurons (and beyond) in the macaque brain: An overview of 20 years of research. Neuroscience Letters, 54O, 3-14. http://www.sciencedirect.com/science/article/pii/ So304394012014589

Coch, D., \& Ansari, D. (2009). Thinking about mechanisms is crucial to connecting neuroscience and education. Cortex, 45(4), 546-547. http://www.sciencedirect.com/science/article/pii/ So010945208001585

Cole, M., \& Scribner, S. (1978). Introduction. I M. Cole, V. John-Steiner, S. Scribner, \& E. Souberman (Eds.), Mind in Society. The Development of Higher Psychological Processes. (pp. 1-14). Cambridge, Massachusetts: Harvard University Press.

Delgado, C. (2014). Collective landmarks for deep time: a new tool for evolution education. Journal of Biological Education, 48(3), 133-141.

DeYoung, C. G., Cicchetti, D., Rogosch, F. A., Gray, J. R., Eastman, M., \& Grigorenko, E. L. (2011). Sources of cognitive exploration: Genetic variation in the prefrontal dopamine system predicts Openness/Intellect. Journal of Research in Personality, 45(4), 364-371.

di Pellegrino, G., Fadiga, L., Fogassi, L., Gallese, V., \& Rizzolatti, G. (1992). Understanding motor events: a neurophysiological study. Experimental Brain Research, 91(1), 176-180. http://dx.doi. org/10.1007/BFo0230027 
Dunbar, R. I. M. (2003). The Social Brain: Mind, Language, and Society in Evolutionary Perspective. Annual Review of Anthropology, 32(1), 163-181. http://search.ebscohost.com/login.aspx?direc $\mathrm{t}=$ true \&db=aph\&AN=11275418\&site=ehost-live

Edelenbosch, R., Kupper, F., Krabbendam, L., \& Broerse, J. E. W. (2015). Brain-Based Learning and Educational Neuroscience: Boundary Work. Mind, Brain, and Education, 9(1), 40-49. http:// dx.doi.org/10.1111/mbe.12066

Farah, M. J., Illes, J., Cook-Deegan, R., Gardner, H., Kandel, E., King, P., et al. (2004). Neurocognitive enhancement: what can we do and what should we do? Nature Reviews Neuroscience, 5(5), 421-425. http://search.ebscohost.com/login.aspx?direct=true\&db=aph\&AN=12887000\&site= ehost-live

Fischer, K. W., \& Heikkinen, K. (2010). The Future of Educational Neuroscience. I D. A. Sousa (Ed.), Leading Edge : Mind, Brain, and Education : Neuroscience Implications for the Classroom (pp. 249-269). Bloomington, IN, USA: Solution Tree Press.

Gardner, H. (2009). An Education Grounded in Biology: Interdisciplinary and Ethical Considerations. Mind, Brain, and Education, 3(2), 68-73.

Geary, D. C. (2008a). An evolutionary informed education science. Educational Psychologist, 43(4), 179-195.

Geary, D. C. (2008b). Whither evolutionary educational psychology? Educational Psychologist, 43(4), 217226.

Geary, D. C. (2009). The Why of Learning. Educational Psychologist, 44(3), 198-201.

Ginsburg, S., \& Jablonka, E. (2010). The evolution of associative learning: A factor in the Cambrian explosion. Journal of Theoretical Biology, 266(1), 11-20. http://www.sciencedirect.com/science/article/pii/Soo22519310003073

Gog, T. v., Paas, F., Marcus, N., Ayres, P., \& Sweller, J. (2009). The Mirror Neuron System and Observational Learning: Implications for the Effectiveness of Dynamic Visualizations. Educational Psychology Review, 21(1), 21-30.

Halpern, D. F. (2008). How much can evolutionary psychology inform the educational sciences? Educational Psychologist, 43(4), 203-205.

Heyes, C. (2010). Where do mirror neurons come from? Neuroscience \& Biobehavioral Reviews, 34(4), 575-583. http://www.sciencedirect.com/science/article/pii/So149763409001730

Hickok, G. (2013). Do mirror neurons subserve action understanding? Neuroscience Letters, 54O, 56-58. http://www.sciencedirect.com/science/article/pii/So304394012014462

Hong, S. (2013). Dopamine system: manager of neural pathways. Frontiers in Human Neuroscience, 7(December), 1-10. http://www.ncbi.nlm.nih.gov/pmc/articles/PMC3856400/

Howe, M. L., \& Derbish, M. H. (2010). On the susceptibility of adaptive memory to false memory illusions. Cognition, 115(2), 252-267.

Howe, M. L., \& Otgaar, H. (2013). Proximate Mechanisms and the Development of Adaptive Memory. Current Directions in Psychological Science, 22(1), 16-22.

Iacoboni, M. (2005). Neural mechanisms of imitation. Current Opinion in Neurobiology, 15(6), 632637. http://www.sciencedirect.com/science/article/pii/So959438805001595

Immordino-Yang, M. H. (2008). The Smoke Around Mirror Neurons: Goals as Sociocultural and Emotional Organizers of Perception and Action in Learning. Mind, Brain, and Education, 2(2), 67-73. http://dx.doi.org/10.1111/j.1751-228X.2008.00034.x

Melby-Lervåg, M., \& Hulme, C. (2013). Is Working Memory Training Effective? A Meta-Analytic Review. Developmental Psychology, 49(2), 270-291.

Mesoudi, A., Whiten, A., \& Laland, K. N. (2006). Towards a unified science of cultural evolution. Behavioral and Brain Sciences, 29(4), 329-383.

Moher, D., Liberati, A., Tetzlaff, J., \& Altman, D. G. (2009). Preferred Reporting Items for Systematic Reviews and Meta-Analyses: The PRISMA StatementThe. Annals of Internal Medicine, 151(4), 264-269. http://dx.doi.org/10.7326/0003-4819-151-4-200908180-00135

Nairne, J. S., \& Pandeirada, J. N. S. (2010). Adaptive memory: Nature's criterion and the functionalist agenda. The American Journal of Psychology, 123(4), 381-390. 
Nettle, D. (2009). Beyond nature versus culture: cultural variation as an evolved characteristic. Journal of the Royal Anthropological Institute, 15(2), 223-240.

Ocampo, B., \& Kritikos, A. (2011). Interpreting actions: The goal behind mirror neuron function. Brain Research Reviews, 67(1-2), 260-267. http://www.sciencedirect.com/science/article/pii/ So165017311000191

Otgaar, H., Howe, M. L., Smeets, T., \& Garner, S. R. (2014). Developmental trends in adaptive memory. Memory, 22(1), 103-117.

Oztop, E., Kawato, M., \& Arbib, M. A. (2013). Mirror neurons: Functions, mechanisms and models. Neuroscience Letters, 540, 43-55. http://www.sciencedirect.com/science/article/pii/ So304394012013183

Piaget, J. (1969). Psykologi og pædagogik. København: Hans Reitzels forlag.

Prokop, P., \& Fancovicova, J. (2014). Seeing coloured fruits: utilisation of the theory of adaptive memory in teaching botany. Journal of Biological Education, 48(3), 127-132.

Shohamy, D., \& Adcock, R. A. (2010). Dopamine and adaptive memory. Trends in Cognitive Sciences, 14(10), 464-472.

Shu, D. (2008). Cambrian explosion: Birth of tree of animals. Gondwana Research, 14(1-2), 219240. http://www.sciencedirect.com/science/article/pii/S1342937X07001694

Sinatra, G. M., Doutherland, S. A., McConaughy, F., \& Demastes, J. W. (2003). Intentions and Beliefs in Students' Understanding and Acceptance of Biological Evolution. Journal of Research in Science Teaching, 4O(5), 510-528.

Sinigaglia, C. (2013). What type of action understanding is subserved by mirror neurons? Neuroscience Letters, 54O, 59-61. http://www.sciencedirect.com/science/article/pii/So304394012013602

Smith, A. M. (2007). An essay on the evolution of cognition: Constructing a theoretical conceptual framework. Journal of Physiology-Paris, 101(4-6), 257-272. http://www.sciencedirect.com/science/article/pii/So928425707000617

Snow, C. P. (1960). De to kulturer. Oslo: J. W. Cappelens forlag.

Sousa, D. A. (2010). How Science Met Pedagogy. I D. A. Sousa (Ed.), Leading Edge: Mind, Brain, and Education: Neuroscience Implications for the Classroom (pp. 9-24). Bloomington, IN, USA: Solution Tree Press.

Sperber, D., \& Hirschfeld, L. A. (2004). The cognitive foundations of cultural stability and diversity. Trends in Cognitive Sciences, 8(1), 40-46.

Stanley, J., Gowen, E., \& Miall, R. C. (2010). How instructions modify perception: An fMRI study investigating brain areas involved in attributing human agency. NeuroImage, 52(1), 389-400. http://www.sciencedirect.com/science/article/pii/S1053811910004192

Stanyon, R., \& Bigoni, F. (2014). Sexual selection and the evolution of behavior, morphology, neuroanatomy and genes in humans and other primates. Neuroscience \& Biobehavioral Reviews, 46, 579-590. http://www.sciencedirect.com/science/article/pii/So149763414002504

Sweller, J., \& Sweller, S. (2006). Natural information processing system. Evolutionary Psychology, 4, 434-458.

Tardif, E., Doudin, P.-A., \& Meylan, N. (2015). Neuromyths Among Teachers and Student Teachers. Mind, Brain, and Education, 9(1), 50-59. http://dx.doi.org/10.1111/mbe.12070

VanArsdall, J. E., Nairne, J. S., Pandeirada, J. N. S., \& Blunt, J. R. (2013). Adaptive Memory. Animacy Processing Produces Mnemonic Advantages. Experimental Psychology, 6o(3), 172-178.

Vygotskij, L. S. (2004). Tenkning og tale. Oslo: Gyldendal Akademisk.

Wilson, E. O. (1999). Consilience. The Unity of Knowledge. London: Abacus.

Wilson, S., Darling, S., \& Sykes, J. (2011). Adaptive memory: fitness relevant stimuli show a memory advantage in a game of pelmanism. Psychonomic Bulletin \& Review, 18(4), 781-786.

Wozniak, R. H. (2009). Consciousness, Social Heredity, and Development. The Evolutionary Thought of James Mark Baldwin. American Psychologist, 64(2), 93-101.

Yawei, C., Po-Lei, L., Chia-Yen, Y., Ching-Po, L., Daisy, H., \& Decety, J. (2008). Gender Differences in the Mu Rhythm of the Human Mirror-Neuron System. PLoS ONE, 3(5), 1-7. http://search.

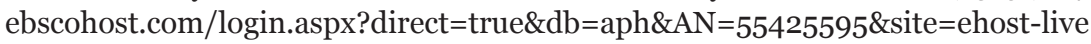

